Acta Universitatis Wratislaviensis

No 3726

Anglica Wratislaviensia LIV

Wrocław 20146

DOI: $10.19195 / 0301-7966.54 .10$

Katarzyna Załóg-Kociuga

University of Wrocław

\title{
The Influence of Deductive and Inductive Instruction on Adolescents' Acquisition of English Vowels
}

\begin{abstract}
Difficulties in mastering the pronunciation of a foreign language arise due to numerous factors, among which the differences between the learners' L1 and L2 seem to be significant. For Polish learners of English, these differences would include considerable disparities between the two vowel systems, which is why the subject of this study are difficult English vowels. The difficulty of vocalic sounds is judged according to Prator's (1967) Hierarchy of Difficulty.

The study aims at determining whether deductive and inductive formal types of phonetic instruction have any influence on the intelligible pronunciation of the most difficult English vowels for Polish 13-year-old learners. Two groups of students were subject to an experiment in which they were taught English pronunciation for 5 weeks: the first group deductively, the second group inductively. Their pronunciation proficiency was tested before and after the teaching sessions by recording the subjects reading a text composed of words containing the tested phonemes.

The comparison of the recordings revealed that while the deductive techniques did not yield any statistically significant improvement in the pronunciation of any of the tested vowels, the inductive techniques significantly improved the learners' pronunciation of [i:], [æ] and [ə] in the interconsonantal context. The conclusion to be drawn is that increased aural exposure, imitation and meaning-focused practice yield better results than providing theoretical, metalinguistic information about the sounds, comparing L1 and L2 sounds and pronunciation-focused practice, at least for young adolescent learners, who may not yet be ready to comprehend abstract phonetic notions.
\end{abstract}

Keywords: deductive instruction, inductive instruction, pronunciation, vowel systems, hierarchy of difficulty, metalinguistic information

\section{Introduction}

Foreign language pronunciation has always been considered particularly difficult to acquire, and therefore, a foreign accent is usually a noticeable indication of being a non-native speaker of a language. The acquisition of foreign phonetics and 
phonology may be influenced by several factors, both internal, such as personality and motivation (e.g. Baran-Łucarz 2007), age (Singleton and Ryan 2004) or different types of aptitude (e.g. Nardo and Reiterer 2009), and external, such as the differences between L1 and L2 (e.g. Purcell and Suter 1980) or the type of instruction (e.g. MacDonald et al. 1994; Elliott 1995; Couper 2003; Kissling 2013). Multiple studies on the importance and the types of pronunciation instruction offer often contradictory, and therefore inconclusive results. Hence, further investigation of the subject, especially on a narrow range of sounds, appears to be reasonable.

As was mentioned above, the difficulties in L2 phonetic and phonological acquisition may result from many factors, one of them being the differences between the learner's L1 and L2, which cause interference. In the case of Polish learners of English, the Poles' accent is influenced, among other factors, by considerable differences between the phonetic and phonological systems of the two languages, and especially by the differences between their vowel systems. Specifically, these differences would include vowel quality, vowel length and vowel reduction. Due to these multiple disparities, studies on the acquisition and teaching of English vowels are important and necessary.

This experimental study aims at determining whether deductive and inductive phonetic instruction have any influence on young adolescents' correct pronunciation of selected vocalic sounds of English. Adolescent learners have been chosen as subjects since they are in a cognitive stage in which deductive reasoning develops. The criterion for choosing the phonemes to research is their level of difficulty according to Prator's (1967) Hierarchy of Difficulty (see section 2.1. The Contrastive Analysis Hypothesis and the Hierarchy of Difficulty). Specifically, the effect of deductive and inductive phonetic instruction is researched on the vowels [I], [i:], [ə], [3:] and [æ]. This influence is measured by comparing the results of a pronunciation test obtained from two groups of students: one group receiving deductive and the second group receiving inductive pronunciation training.

\section{The acquisition and teaching of phonetics and phonology}

Foreign language learners are often unable to obtain native-like or at least intelligible L2 pronunciation, despite having learned or having been exposed to a language for several years. Their phonetic and phonological acquisition may be influenced by many factors, such as the type of instruction, the learners' L1, age, motivation or personality traits (Flege et al. 1995). For the purpose of the present research, only the importance of the learners' L1 and the type of instruction will be described in detail. 


\subsection{The role of $\mathrm{L} 1$}

The learner's L1 plays a significant role in their L2 phonetic and phonological acquisition. Specifically, Flege (1992: 565) claims that adults learning an L2 have access to an already established phonetic system, which is why they are likely to commit errors resulting from the incorrect use of previously acquired forms. According to Ellis (2008: 368), phonological transfer is selective in nature, that is, learners do not constantly transfer L1 phonological features to L2 utterances. However, as Flege (1992: 566) states, learners, especially at the earliest stages, often substitute an unfamiliar L2 phoneme with a familiar sound from their L1, i.e. the L2 words are composed of L1 phonemes. In order to produce native-like foreign sounds, a learner has to reestablish their already defined system of sound patterns. This process usually takes place at late stages of acquisition. However, it is believed that some learners are not able to achieve it. As a result, the target sounds which are non-existent or do not have close equivalents in the native language may be difficult to acquire and pronounce. Such claims were advocated by the supporters of the Contrastive Analysis Hypothesis (e.g. Stockwell and Bowen 1965; Prator 1967).

However, difficulties in acquiring L2 phonetics and phonology arise not only when a phoneme is new and unfamiliar, but also when it has an L1 equivalent. As the supporters of the Speech Learning Model (Flege 1995) and the Similarity Differential Rate Hypothesis (Major and Kim 1999) claim, learners often do not discriminate between equivalent L1 and L2 sounds, even though their places of articulation may be different or they appear in different contexts or positions in the two languages. Since the differences between the phonemes are not noted, no new mental phonetic category can be created for the L2 sound, which is why it is realised exactly like an L1 sound. On the other hand, the more dissimilar an L2 sound is, the more the learner is likely to create a new phonetic category for it.

\subsection{Types of instruction}

The distinction between formal and informal instruction is concerned with the environment of the learning process. Formal instruction takes place in a classroom setting and is aimed at developing linguistic and communicative competences as well as learning strategies. By contrast, informal instruction takes place outside the classroom setting.

Formal instruction may take the form of deductive or inductive instruction. According to Ellis (2008: 882), in deductive instruction, which is form-focused, the learners are given the L2 rules explicitly and practise structures only after the rule is presented. In inductive instruction, on the other hand, they should induce the rules from the examples and practice activities given to them. 
1.3. Formal instruction, its types and their effect on pronunciation accuracy

In most studies on the types of formal pronunciation instruction and their effects, researchers use the terms 'explicit' and 'implicit', rather than 'deductive' and 'inductive', even though they are often defining very similar, or even identical techniques. The studies referred to below are cited along with their own terminology, although what their authors operationalised as explicit pronunciation instruction is what I have operationalised as deductive pronunciation instruction, even though both deductive and inductive types of instruction are explicit in their nature, as they both concentrate on rule internalisation.

Pennington and Richards (1986) concluded that there is little evidence that pronunciation instruction on either a segmental or a suprasegmental level is efficient and, more importantly, that in fact any type of pronunciation instruction is effective at all. Similarly, MacDonald et al. (1994), who investigated the effects of different types of formal instruction, concluded that "no single intervention was beneficial to all learners who experienced it (p. 94)."

By contrast, Elliott (1995), confirmed that 'multimodal' pronunciation training consisting of both deductive and inductive techniques improved learners' pronunciation accuracy. Couper (2003), in turn, researched the effects of explicit instruction on both segmental and suprasegmental features, also determining that it was beneficial for learners. Szyszka's study (2003) showed that students who were taught English phonetics with the help of phonemic transcription outperformed those who received phonetic training excluding the use of this tool.

Stasiak and Szpyra-Kozłowska (2003) indicated that both deductive and inductive phonetic instruction techniques were beneficial as long as learners received the training regularly. However, no advancement was noted in the pronunciation of certain phonemes, such as [æ] or [ə] and other weak forms, regardless of the teaching mode. Similarly, Kissling (2013) investigated the effects of explicit and implicit phonetic instruction. Since the improvement shown by both groups in the post-test was the same, the conclusion was that "it might be the input, practice, and/or feedback included in pronunciation instruction, rather than the explicit phonetics lessons, that are most facilitative of improvement in pronunciation (720)."

As can be seen, numerous studies on the effects of explicit vs. implicit/deductive vs. inductive pronunciation teaching techniques offer contradictory conclusions. Some studies reject the importance of any type of formal instruction, while others indicate that any type of instruction is effective under certain conditions, and yet others suggest that explicit/deductive techniques yield better results than implicit/ inductive ones. 


\section{The comparison of Polish and English vowel systems}

The differences between the two languages' sound systems can be evaluated from two perspectives: the greater the similarity, the greater the difficulty (according to the Speech Learning Model) or the greater the difference, the greater the difficulty (according to the Contrastive Analysis Hypothesis). For the purpose of this study, I chose the second perspective, which is why this chapter is devoted to the Contrastive Analysis Hypothesis and the most significant differences between the Polish and English vowel systems. The reason for my choice of the Contrastive Analysis Hypothesis is that Polish learners' inaccurate realization of new/dissimilar sounds is more conspicuous to a native ear and more likely to cause communication breakdowns than inaccurately realised or transferred equivalent/similar sounds (Sobkowiak 2004: 132-164).

\subsection{The Contrastive Analysis Hypothesis and the Hierarchy of Difficulty}

The Contrastive Analysis Hypothesis (CAH), originally formulated by Lado (1957), aims at determining which L2 forms are easy or difficult to acquire due to their similarity or dissimilarity to L1 forms. The comparison of two languages allows us to predict which areas will be difficult and consequently, where the errors will most probably occur. The learner's native language is perceived as the main source of errors in L2 utterances.

The processes of comparing two languages and predicting the problematic areas resulted in the establishing of several rankings of structures which may pose difficulties. Such hierarchies were formulated e.g. by Stockwell and Bowen (1965) and Stockwell, Bowen and Martin (1965). These were applicable to the phonology and to the grammatical structures of two languages respectively, and they ranked the items depending on whether they occur in both languages, whether they occur in them in similar contexts, and whether they have one or more equivalents. The latter hierarchy was then reformulated by Prator (1967), whose version was applicable to both grammar and phonetics. The hierarchy consists of 6 levels (0-5), in which the items comprising the fourth level, i.e. the ones that have to be learned as new, and the ones comprising the fifth level, i.e. the ones which have to be discriminated between, are the most difficult to acquire.

Although towards the end of the 20th century contrastive-analysis-based approaches to pronunciation teaching were gradually losing support and popularity (Jenkins 2004), the approaches which incorporate raising learners awareness of L1/ L2 differences into EFL teaching are starting to be again perceived as useful (e.g. Ammar et al. 2010). Contrastive analysis continues to constitute a basis for many linguistic and SLA studies. For example, Mair (2005) and Laufer and Girsai (2008) acknowledged that the comparison of two languages is helpful in creating language awareness. Thus, even though the assumptions of the CAH cannot account for all 
mistakes occurring in L2 utterances, direct comparisons of L1 and L2 have been beneficial for many learners and as a result, have been used at various levels of proficiency by numerous teachers.

\subsection{Phonetic differences between Polish and English vowels}

The difficulties that Polish learners encounter in L2 English phonetic acquisition result from significant qualitative and quantitative differences between the Polish and English vowel systems. Specifically, as Sobkowiak (2004: 130) claims, the differences include tongue position, vowel length (contrastive in English, but not in Polish), vowel reduction (absent in Polish) and nasalisation (heavier in Polish). What is more, the English vowel system consists of twice as many oral vowels as the Polish one and there are no equivalent phonemes between the two languages. The discrepancies in the tongue positions of the Polish and the English vowels are visible in the diagram below (Polish vowels in brackets):

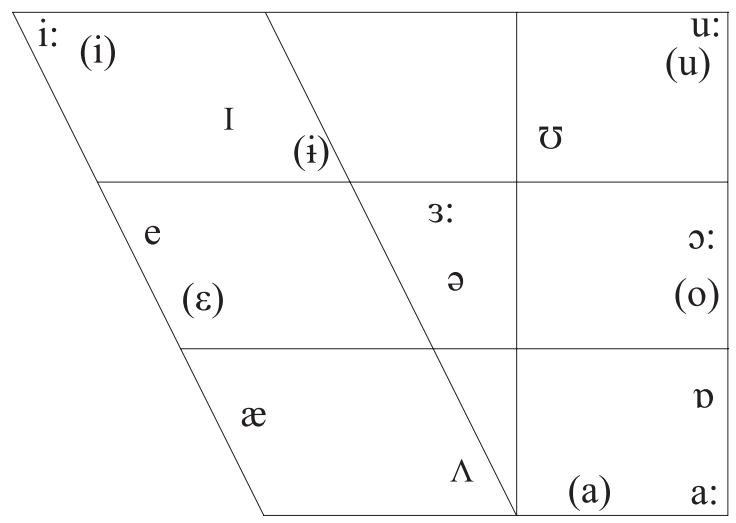

Figure 1. English and Polish vowels (adapted from Sobkowiak 2004: 53)

The English vowels belonging to the fourth level of Prator's (1967) Hierarchy of Difficulty for Polish learners, i.e. phonemes present in English but absent in Polish, are the mid central vowels [3:] and [ə] and a low front vowel [æ]. The sounds belonging to the highest level of the hierarchy, i.e. sounds which have to be discriminated between since they have one common equivalent in Polish, are the high front [i: ] and [I].

The Polish vowel system, unlike the English one, does not include mid central vowels. As Szymaniuk (2008: 33) describes, while the English phonemes [ə] and [3:] are being articulated, the central part of the tongue should be slightly raised with its surface remaining flat, while the lips should remain in a neutral position. According to Sobkowiak (2004: 132, 138), theoretically, the sounds should not be difficult to articulate due to their neutral tongue position. In practice, however, Polish learners consistently substitute them with Polish phonemes, such as $[\varepsilon]$ or 
[i] (for [ə]) and [ع] or [o] (for [3:]), which may lead to communication breakdowns. What is more, [ə] is often reduced, especially in an interconsonantal context. Polish learners, whose language gives equal importance to each sound and syllable, find vowel reduction rather difficult, especially at the early stages of acquisition.

The sound [æ] does not have any equivalents in Polish either. What is more, as Sobkowiak (2004: 142) states, it is similar neither to the Polish [a], which is much less front, nor to the Polish $[\varepsilon]$, which is higher. In fact, the phoneme [æ]is intermediary between the Polish [a] and [ $\varepsilon]$, which is why both these phonemes usually serve as substitutes for it. The acquisition is difficult also because the English vowel system discriminates four low vowels, while the Polish one includes only one. As a result, Polish learners of English may have difficulties in perceiving contrasts between $[æ],[\Lambda]$ and $[\mathrm{a}:]$.

Finally, the high front vowels [i:] and [I] comprise another source of communication breakdowns between Polish learners and English native speakers. As Szymaniuk (2008: 34) states, while [i:] is being articulated, the lips are spread and the front part of the tongue is raised. It is articulated similarly to its equivalent Polish phoneme [i], however, unlike [i], it is diphthongised, that is, it resembles the cluster $/ \mathrm{ij} /$, and is thus pronounced longer than its Polish counterpart.

The sound $[\mathrm{I}]$, in turn, is pronounced with spread lips and a slightly retracted tongue, though still in the front part of the oral cavity. Its Polish counterpart, however, is articulated with the tongue slightly lifted and moved forward, and lips spread less than while pronouncing [i]. The phoneme [I] may be difficult to pronounce for Polish learners because of its intermediary position between Polish [i] and [i].

An accurate realisation of the phonemes [i: and [I] is especially important, since they often appear in the context of minimal pairs, that is, they are the only contrastive phonemes in a pair of words. Specifically, communication breakdowns occur when Polish learners substitute both English [i: and [I] with one Polish sound interpolated between them, i.e. [i]. For instance, English native speakers hearing / liv/ pronounced by a Polish speaker may not recognise whether the speaker means "live" / liv/ or "leave" / li:v/.

\section{The research}

The research aims at discovering the possible effects of deductive and inductive types of phonetic instruction on adolescent learners' pronunciation of given English vowels. Specifically, the problems to address are the influence of training on the acquisition of a foreign vowel system and the existence of a relationship between the type of training and an intelligible vowel realisation.

The choice of subjects at the age of 13 aims at discovering whether early adolescents who have just entered the formal operational stage of cognitive development 
(Inhelder and Piaget 1958), in which deductive reasoning ability develops, are already able to benefit from deductive, metalinguistic instruction, or whether they should be still instructed as at earlier stages of development, i.e. inductively.

The research questions are as follows:

1) Is deductive phonetic instruction more effective in teaching the pronunciation of the most difficult English vowels to adolescents?

2) Is inductive phonetic instruction more effective in teaching the pronunciation of the most difficult English vowels to adolescents?

\subsection{The setting and the participants}

The research was conducted in September and October 2013. The subjects were two groups of 13-year-old students of both sexes, attending the first grade of lower secondary school. Both groups consisted of 14 subjects who were at the same level of proficiency (CEFR level A1/A2), which was verified by a general proficiency test and a t-test correlation calculated on the basis of its results obtained in both groups. The two groups used the same coursebook (Next Move 2) and attended ELT classes at school 3 times a week for 45 minutes. All the subjects had started learning English at the age of 6-7.

The teacher who conducted the lessons during the experiment was a nonnative speaker of English who has spent several years abroad among native speakers. His accent was evaluated by two native English speakers who concluded that his pronunciation was native-like enough for him to be a good imitation model for the learners.

\subsection{The research procedure}

The experiment started with recording each subject individually, reading a specially prepared text ${ }^{1}$ composed of words which contained the vowels being researched (pre-test). After the recording, the process of training, which lasted for 5 weeks, began. Each group received 15 ELT sessions in which phonetic training of a specific type was incorporated.

The words which the text was composed of were very carefully chosen and taken from the early units of the learners' coursebook. Such a careful word choice aimed at minimalising the limitations of the reading procedure, specifically, at minimalising the impact of spelling pattern interference. The learners knew the

1 The text reads as follows: "Tim is thirteen. He lives in London. He's a football fan. His favourite team is Manchester United. He often watches them on the pitch and he has a Manchester t-shirt. His dad is Turkish. He's thirty-nine and works as a policeman. Tim got a camera for his birthday. Now he often takes photos of his garden, his cat, and birds on peach trees. He also likes history lessons and having fun with his girlfriend. She is keen on fashion and she talks about bags and shoes. His dream is to leave London and go on a trip around the world. Today, Tim is a bit happy, because he has acting classes at school." 
words used in the experiment and were familiar, at least theoretically, with their correct pronunciation.

Group 1 received deductive phonetic training, which concentrated both on the theory and practice of English phonetics. The teaching sessions included some elements of contrastive analysis, that is, the languages' phonetic systems were compared and the most striking differences between them were emphasised. The learners were taught phonetic transcription, i.e. they were presented with the English sounds and their graphic representations, which aimed not only at teaching them how to recognise phonetic symbols, but also how to read them properly in new contexts, e.g. while learning new vocabulary items. The sounds were practised both in isolation and in context, both in form-focused (pronunciation-focused) and meaning-focused activities. The contrast between long and short vowels was practised by means of receptive and productive exercises on vowel minimal pairs. Some theoretical explanations were included in error correction, but not necessarily in all instances.

Group 2 received inductive phonetic training, which consisted in increased aural exposure to the L2 in a classroom setting. The training resembled natural L2 exposure, i.e. the learners should learn pronunciation inductively, without being taught any theory. Instead of teaching English pronunciation by means of sound description and rule explanation, the teacher provided an imitation model for the learners and corrected their mistakes without offering any theoretical explanations. Pronunciation was practised only in the form of meaning-focused activities.

For ethical reasons, no control group was included in this study, as students in such a group would have had to receive no pronunciation instruction whatsoever, that is, pronunciation would have to be completely neglected. Since such a procedure might have been harmful for the learners, the idea was abandoned.

After 5 weeks of pronunciation training, each learner was once again recorded individually, reading the same text as before the training (post-test). The two recordings of each subject were later thoroughly analysed and compared by two native speakers of English, who estimated the numbers of intelligible vocalic phonemes in the pre-test and in the post-test. The vowel was rated intelligible if its realisation carried no risk of misunderstanding without providing any context. For example, if the learner uttered /pitf/ for 'pitch' or / pi:tf/ for 'peach', their realisation was rated intelligible. By contrast, if they uttered / pit5/, the realisation was rated unintelligible, since the meaning ('pitch' or 'peach') cannot be inferred without context. The intelligibility of consonants and vowels other than those being researched was ignored.

\subsection{The research results}

The rating procedure aimed at establishing the numbers of intelligible realisations of given vowels by each learner. The numbers of phonemes pronounced intelligibly were analysed statistically: firstly, I tested whether they constituted a 
normal distribution (the Shapiro-Wilk test) and then I examined their statistical significance with the use of t-Student test for two dependent means (two-tailed, $\mathrm{p}=.05$ ) if the sample was normally distributed and with the use of Wilcoxon signed-rank (two-tailed, $\mathrm{p}=.05$ ) if it was not normally distributed (in the table represented in bold). Only the shaded figures turned out to be statistically significant.

Table 1. Mean and standard deviation values of intelligible realisations of specific vowels, along with their t-values (for t-Student test) or W-values (for Wilcoxon signed-rank test — in bold) and p-values

\begin{tabular}{|c|c|c|c|c|c|c|c|}
\hline & \multicolumn{4}{|c|}{ Deductive phonetic training } & \multicolumn{3}{|c|}{ Inductive phonetic training } \\
\hline & \multicolumn{2}{|c|}{ Mean scores / SD } & \multirow{2}{*}{$\mathrm{t} / \mathrm{W}$} & \multirow{2}{*}{$\mathrm{p}$} & \multicolumn{2}{|c|}{ Mean scores / SD } & \multirow{2}{*}{$\mathrm{t} / \mathrm{W}$} \\
\hline & Pre-test & Post-test & & & Pre-test & Post-test & \\
\hline [3:] (0-9) & $\begin{array}{l}3.0 \\
/ 1.84\end{array}$ & $\begin{array}{l}3.79 \\
/ 1.97\end{array}$ & 1.99 & .068 & $\begin{array}{l}2.36 \\
/ 2.24\end{array}$ & $\begin{array}{l}2.64 \\
/ 2.1\end{array}$ & 1.47 \\
\hline initial [ə] (0-2) & $\begin{array}{l}1.21 \\
/ 0.8\end{array}$ & $\begin{array}{l}1.43 \\
/ .65\end{array}$ & 3.0 & .22 & $\begin{array}{l}1.14 \\
/ .77\end{array}$ & $\begin{array}{l}.86 \\
/ .86\end{array}$ & 10.5 \\
\hline $\begin{array}{l}\text { interconsonantal } \\
\text { [ə] }(0-9)\end{array}$ & $\begin{array}{l}3.14 \\
/ 1.29\end{array}$ & $\begin{array}{l}3.21 \\
/ 1.05\end{array}$ & .21 & .836 & $\begin{array}{l}2.79 \\
/ 2.12\end{array}$ & $\begin{array}{l}3.5 \\
/ 2.41\end{array}$ & 2.92 \\
\hline$[æ](0-14)$ & $\begin{array}{l}8.29 \\
/ 2.87\end{array}$ & $\begin{array}{l}9.21 \\
/ 2.15\end{array}$ & 1.87 & .084 & $\begin{array}{l}7.5 \\
/ 3.67\end{array}$ & $\begin{array}{l}8.79 \\
/ 3.45\end{array}$ & 3.03 \\
\hline$[\mathrm{I}](0-7)$ & $\begin{array}{l}2.07 \\
/ 1.6\end{array}$ & $\begin{array}{l}2.79 \\
/ 1.67\end{array}$ & 1.41 & .453 & $\begin{array}{l}1.93 \\
/ 1.81\end{array}$ & $\begin{array}{l}2.29 \\
/ 1.90\end{array}$ & 10.0 \\
\hline [i: $(0-7)$ & $\begin{array}{l}2.14 \\
/ 1.46\end{array}$ & $\begin{array}{l}2.43 \\
/ 1.7\end{array}$ & .77 & .183 & $\begin{array}{l}1.5 \\
/ 1.34\end{array}$ & $\begin{array}{l}2.21 \\
/ 1.58\end{array}$ & 2.22 \\
\hline
\end{tabular}

As can be seen, most of the improvements and the declines observed in the learners' utterances are not statistically significant, although the mean values of intelligible realisations of given vowels increase between the pre-test and the posttest. Statistically significant improvements were noted only in the post-test after the inductive phonetic instruction. Specifically, the improvement was observed in the realisation of the vowels [æ], [i:] and [ə] in the utterance interconsonantal position. No statistically significant improvement was noted after the deductive phonetic instruction.

\subsection{Conclusions}

The first conclusion to be drawn from the collected data is that the subjects' pronunciation proficiency is rather low. The pronunciation of the majority of the vowels being researched (apart from [æ] and [ə] in the utterance initial position) was incorrect on average in about $2 / 3$ of cases in both recordings, even though modest improvements were noted after the experiment. 
Evidently, the inductive training had a rather strong positive effect on the learners' pronunciation of the sound [ə] in the utterance interconsonantal position. The reason for the lack of statistical improvement after the deductive training might be the age of the learners, for whom the theory of a reduced vowel might be too abstract. By contrast, imitating a role model was a successful method of learning to pronounce /o/ in interconsonantal contexts. Apparently, it was more difficult for the learners to master the sound's neutral tongue position, which they heard about during the deductive training, than to imitate its reduced version in word context, which they did during the inductive one, especially since the learners had been exposed to the correct pronunciation of the words containing the reduced / $/$ /, such as 'lesson' or 'London' multiple times. However, the subjects' pronunciation was tested only on familiar words. Thus, their ability to pronounce and reduce [ə] in new contexts, e.g. in new vocabulary items, is an area for further investigation.

Inductive phonetic training had a strong positive effect on the pronunciation of [i:]. The reason for such differences might be similar to the case of [ə] in the interconsonantal position, that is, that the theory of short and long sounds may be too abstract for most young subjects. The notion of a long sound might seem unnatural, and as a result young learners might be skeptical and reluctant to produce long phonemes. However, apparently, when the learners hear the long vowels, but are not instructed about their length, they are able to perceive and produce them accurately.

Interestingly, in the case of [æ], focusing the learners' attention on the fact that the vowel is intermediary between two Polish sounds known to them was much less helpful than increased aural exposure and imitation. It was the inductive teaching techniques that resulted in significantly better pronunciation of the phoneme in the post-test.

The use of deductive pronunciation teaching techniques, such as teaching phonetic transcription, elements of contrastive analysis and introducing information about the sound's place of articulation did not appear to be beneficial for young learners. It is reasonable to assume that the learners' young age had a strong effect on the results of the experiment, that is, that the learners were too young to comprehend a lot of deductive and explicit phonetic information. Fortunately, however, providing a lot of theoretical phonetic information did not have a negative effect on their pronunciation accuracy.

In conclusion, as the research indicates, increased aural language exposure and imitation facilitates the pronunciation of three of the most difficult English vowels for young adolescent Polish learners of English. Deductive pronunciation teaching techniques, such as providing theoretical phonetic descriptions, introducing phonetic transcription, using elements of contrastive analysis and form (pronunciation)-focused practice in EFL courses does not yield such good results as inductive techniques and practice. Learners should be able to achieve intelligible pronunciation of the vowels [æ], [i:] and [ə] in the interconsonantal position as long as they are provided with a good model to imitate, practise by means of 
meaning-focused activities and provided they receive corrective feedback. Even though theoretically13-year-olds are capable of deductive reasoning, the results obtained in the research suggest that at such an age, inductive teaching techniques, which do not require the use of metalanguage, yield better results than deductive ones. Thus, it is recommended to use inductive teaching techniques in pronunciation training for young adolescents.

\section{References}

Ammar, A., P.M. Lightbown and N. Spada. 2010. "Awareness of L1/L2 differences: Does it matter?" Language Awareness 19. 129-146.

Baran-Łucarz, M. 2007. "Profiles of Excellent, Very Good, and Very Poor Foreign Language Pronunciation Learners." In: Wrembel, M. (ed.) IATEFL Pronunciation Special Interest Group Speak Out! A Special Issue 'From Poland with Phon' 38, 5-10.

Couper, G. 2003. "The value of an explicit pronunciation syllabus in ESOL teaching." Prospect 18. $53-70$.

Elliott, R. 1995. "Foreign language phonology: Field independence, and the success of formal instruction in Spanish pronunciation." The Modern Language Journal 79. 530-542.

Ellis, R. 2008. The Study of Second Language Acquisition. New York: Oxford University Press.

Flege, J. 1992. "Speech Learning in a Second Language." In: Ferguson, C., L. Menn and C. StoelGammon (eds.) Phonological Development: Models, Research, and Application. Timonium, MD: York Press, 565-604.

Flege, J. 1995. "Second Language Speech Learning: Theory, Findings and Problems." In: Strange, W. (ed.) Speech Perception and Linguistic Experience Issues in Cross-Language Research. Timmonium, MD: York Press, 229-273.

Flege, J., M. Munro and I. MacKay. 1995. "Factors affecting strength of perceived foreign accent in a second language."Journal of the Acoustical Society of America 97. 3125-3134.

Inhelder, B. and J. Piaget. 1958. The Growth of Logical Thinking From Childhood to Adolescence (A. Parsons and S. Milgram, Trans.). New York: Basic Books.

Jenkins, J. 2004. "Research in teaching pronunciation and intonation." Annual Review of Applied Linguistics 24. 109-125.

Kissling, E. 2013. "Teaching pronunciation: Is explicit phonetic instruction beneficial for FL learners?” The Modern Language Journal 97.3. 720-744.

Lado, R. 1957. Linguistics Across Cultures. Ann Arbor: University of Michigan Press.

Laufer, B. and N. Girsai 2008. "Form-focused instruction in second language vocabulary learning: A case for contrastive analysis and translation." Applied Linguistics 29. 694-716.

MacDonald, D., G. Yule and M. Powers. 1994. "Attempts to improve English L2 pronunciation: The variable effects of different types of instruction." Language Learning 44. 75-100.

Mair, C. 2005. "Recent Advances in Contrastive Linguistics and Language Typology: The Spin-off for Language Teachers." In: Allerton, D.J., C. Tschichold and J. Wieser (eds.) Linguistics, Language Teaching and Language Learning. Basel: Schwabe, 21-39.

Major, R. and E. Kim. 1999. "The similarity differential rate hypothesis." Language Learning 49. 151-183.

Nardo, D. and S.M. Reiterer. 2009. "Musicality and Phonetic Language Aptitude.” In: Dogil, G. and S.M. Reiterer (eds.) Language Talent and Brain Activity. Trends in Applied Linguistics. Berlin: De Gruyter, 213-255.

Pennington, M. and J. Richards. 1986. "Pronunciation revisited." TESOL Quarterly 20. 207-225. 
Prator, C. 1967. Hierarchy of Difficulty. Unpublished classroom lecture, University of California, Los Angeles.

Purcell, E. and R. Suter. 1980. "Predictors of pronunciation accuracy: A reexamination." Language Learning 18. 27-67.

Roach, P. 2004. "British English (Received Pronunciation)." Journal of the International Phonetic Association 34.2. 239-245.

Singleton, D. and L. Ryan. 2004. Language Acquisition: The Age Factor. Clevedon: Multilingual Matters.

Sobkowiak, W. 2004. English Phonetics for Poles. Poznań: Wydawnictwo Poznańskie.

Stasiak, S. and J. Szpyra-Kozłowska. 2003. "The Effectiveness of Selected Pronunciation Teaching Techniques." In: Sobkowiak, W. and E. Waniek-Klimczak (eds.) Zeszyty Naukowe Państwowej Wyższej Szkoły Zawodowej w Koninie. Zeszyt Naukowy Instytutu Neofilologii 1.2. Konin: Wydawnictwo PWSZ w Koninie, 125-131.

Stockwell, R. and J. Bowen. 1965. The Sounds of English and Spanish. Chicago: University of Chicago Press.

Stockwell, R., J. Bowen and J. Martin. 1965. The Grammatical Structures of English and Spanish. Chicago: University of Chicago Press.

Szymaniuk, D. 2008. "Segmental Phonetics." In: Miatluk, A. (ed.) Contrastive Phonetics of English and Polish: Phonetic Interference. Białystok: Trans Humana, 29-84.

Szyszka, M. 2003. "Efekty dydaktyki wymowy języka angielskiego w oparciu o transkrypcję fonemiczną." In: Sobkowiak, W. and E. Waniek-Klimczak (eds.) Zeszyty Naukowe Państwowej Wyższej Szkoły Zawodowej w Koninie. Zeszyt Naukowy Instytutu Neofilologii 1.2. Konin: Wydawnictwo PWSZ w Koninie, 145-149. 